\title{
Erratum to: A humanized anti-osteopontin antibody inhibits breast cancer growth and metastasis in vivo
}

\author{
Jianxin Dai · Bohua Li · Jinping Shi · Ling Peng • Dapeng Zhang • Weizhu Qian · \\ Sheng Hou $\cdot$ Lei Zhao $\cdot$ Jie Gao $\cdot$ Zhiguo Cao $\cdot$ Jian Zhao $\cdot$ Hao Wang $\cdot$ Yajun Guo
}

Published online: 7 January 2010

(C) Springer-Verlag 2010

\section{Erratum to: Cancer Immunol Immunother}

DOI 10.1007/s00262-009-0754-z

Unfortunately, in the original publication under the Section "Results" the sentence in the first paragraph for the subheading "Hu1A12 inhibits OPN-mediated anti-apoptotic and prosurvival functions" is incorrectly published as "In the presence of OPN, [3H]thymidine uptake increased $3.08 \pm 0.64$-fold in MDA-MB-435S cells (Fig. 5a). However, this incorporation uptake decreased $2.76 \pm 0.35$-fold when hu1A12 was added" but the correct version is "In the presence of OPN, [3H]thymidine uptake increased $5.02 \pm 0.94$-fold in MDA-MB-435S cells (Fig. 5a). However, this incorporation uptake decreased $3.17 \pm 0.62$-fold when hu1A12 was added".

Figure 5 has been published incorrectly. Please find below the correct version of Fig. 5 .

The online version of the original article can be found under doi: 10.1007/s00262-009-0754-z.

J. Dai · B. Li · J. Shi $\cdot$ L. Peng · D. Zhang · W. Qian · S. Hou ·

L. Zhao $\cdot$ J. Gao $\cdot$ Z. Cao $\cdot$ J. Zhao $\cdot$ H. Wang $\cdot$ Y. Guo $(\bowtie)$

International Joint Cancer Institute and 301 General Hospital, Cancer Center, The Second Military Medical University, 800 Xiang Yin Road, 200433 Shanghai,

People's Republic of China

e-mail: yjguo@smmu.edu.cn

B. Li · D. Zhang · W. Qian · S. Hou · H. Wang $\cdot$ Y. Guo

National Engineering Research Center for Antibody Medicine, 399 Libing Road, 201203 Shanghai,

People's Republic of China 
A

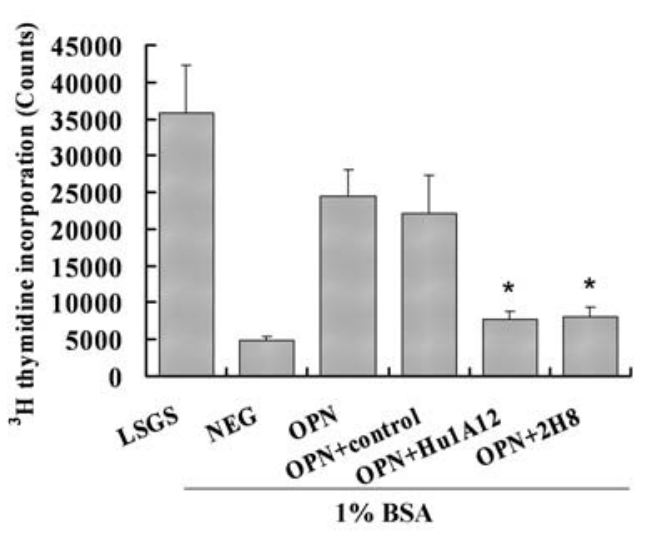

C

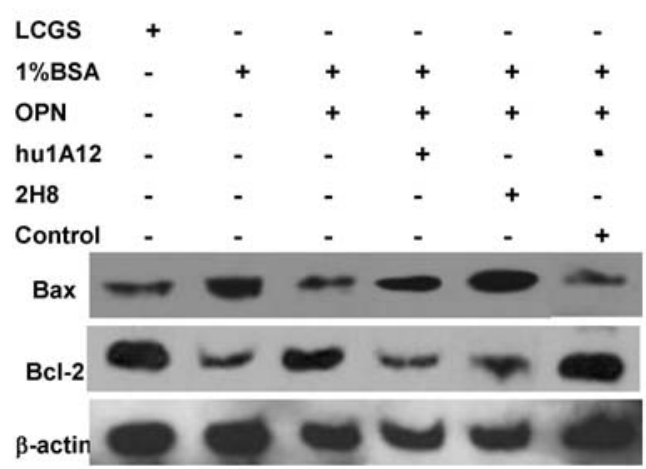

B

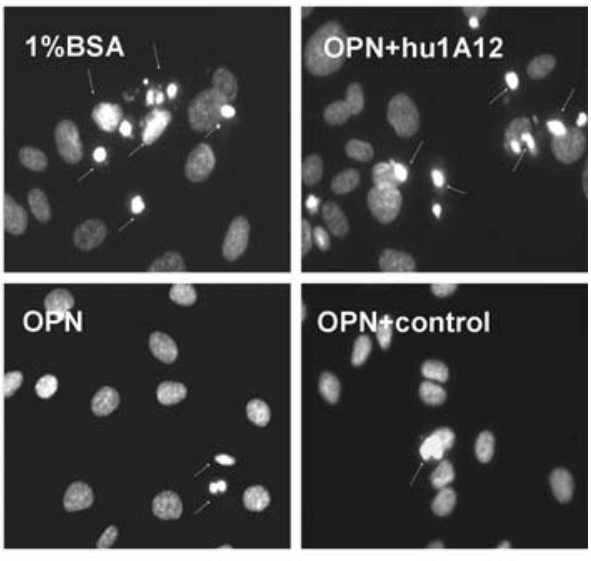

D

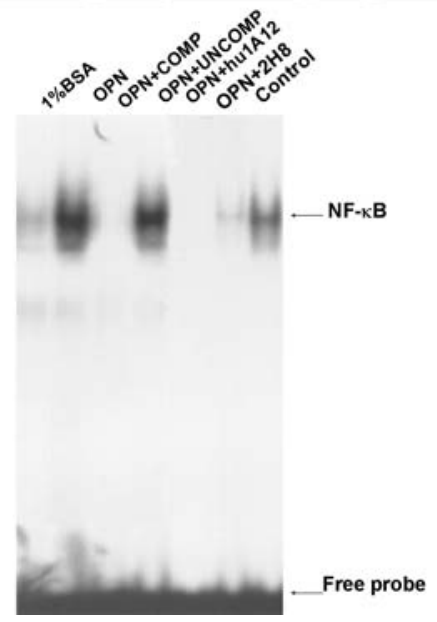

